\title{
Duplication of the NPHP1 gene in patients with autism spectrum disorder and normal intellectual ability: a case series
}

\author{
Yuka Yasuda ${ }^{1}$, Ryota Hashimoto ${ }^{1,2^{*}}$, Ryoko Fukai ${ }^{3,4}$, Nobuhiko Okamoto ${ }^{5}$, Yoko Hiraki ${ }^{6}$, Hidenaga Yamamori ${ }^{1,7}$, \\ Michiko Fujimoto ${ }^{1}$, Kazutaka Ohi ${ }^{1}$, Masako Taniike ${ }^{2}$, Ikuko Mohri ${ }^{2}$, Mitsuko Nakashima ${ }^{4}$, Yoshinori Tsurusaki ${ }^{4}$, \\ Hirotomo Saitsu ${ }^{4}$, Naomichi Matsumoto ${ }^{4}$, Noriko Miyake ${ }^{4}$ and Masatoshi Takeda ${ }^{1}$
}

\begin{abstract}
Autism spectrum disorder is a neurodevelopmental disorder characterized by impairments in social interactions, reduced verbal communication abilities, stereotyped repetitive behaviors, and restricted interests. It is a complex condition caused by genetic and environmental factors; the high heritability of this disorder supports the presence of a significant genetic contribution. Many studies have suggested that copy-number variants contribute to the etiology of autism spectrum disorder. Recently, copy-number variants of the nephronophthisis 1 gene have been reported in patients with autism spectrum disorder. To the best of our knowledge, only six autism spectrum disorder cases with duplications of the nephronophthisis 1 gene have been reported. These patients exhibited intellectual dysfunction, including verbal dysfunction in one patient, below-average verbal intellectual ability in one patient, and intellectual disability in four patients.

In this study, we identified nephronophthisis 1 duplications in two unrelated Japanese patients with autism spectrum disorder using a high-resolution single-nucleotide polymorphism array. This report is the first to describe a nephronophthisis 1 duplication in an autism spectrum disorder patient with an average verbal intelligence quotient and an average performance intelligence quotient. However, the second autism spectrum disorder patient with a nephronophthisis 1 duplication had a below-average performance intelligence quotient. Neither patient exhibited physical dysfunction, motor developmental delay, or neurological abnormalities. This study supports the clinical observation of nephronophthisis 1 duplication in autism spectrum disorder cases and might contribute to our understanding of the clinical phenotype that arises from this duplication.
\end{abstract}

Keywords: Autism spectrum disorder, Copy-number variants, Duplication, Nephronophthisis 1 gene, Intelligence

\section{Background}

Autism spectrum disorder (ASD) is a neurodevelopmental condition characterized by compromised social interactions, reduced verbal communication abilities, stereotyped repetitive behaviors, and restricted interests [1]. The prevalence of ASD is estimated to be 62 in 10,000 individuals, and the number of diagnosed cases has increased in the past decade $[2,3]$. The etiologies of ASD are complex

\footnotetext{
* Correspondence: hashimor@psy.med.osaka-u.ac.jp

'Department of Psychiatry, Osaka University Graduate School of Medicine,

D3, 2-2, Yamadaoka, Suita, Osaka 565-0871, Japan

${ }^{2}$ Molecular Research Center for Children's Mental Development, United

Graduate School of Child Development, Osaka University, D3, 2-2,

Yamadaoka, Suita, Osaka 565-0871, Japan

Full list of author information is available at the end of the article
}

and unclear, and both genetic and environmental factors are hypothesized to be contributors. The following genetic factors have been reported to be associated with of ASD: 2,135 non-syndromic autism-related genes, 99 syndromic autism-related genes, 4,544 copy-number variations (CNVs), and 158 linked regions [4]. Copynumber alterations in the nephronophthisis 1 gene (NPHP1; NM_000272.3) which is located in the 2q13 region have been associated with ASD [5-9]. The genomic region that surrounds NPHP1 is flanked by two inverted low-copy repeats (LCRs), which include $45-\mathrm{kb}$ direct repeats; therefore, deletion or duplication can easily occur in this region via non-allelic homologous recombination, which results in NPHP1 copy-number changes 
[10]. In humans, homozygous or compound heterozygous deletions and loss-of-function mutations in NPHP1 cause ciliopathies such as juvenile nephronophthisis (MIM\# 256100), Joubert syndrome type 4 (MIM\# 609583), and Senior-Loken syndrome 1 (MIM\# 266900) [10,11]. In a 2007 study, 1 of 14 patients with Joubert syndrome type 4 exhibited ASD [12]. Additional studies have confirmed the presence of NPHP1 deletions in individuals with ASD [5-8]. Duplication of the NPHP1 gene has been identified in ASD patients and controls [12,13]. Whether the CNV in this gene is a normal variant is unknown $[7,13]$. Six individuals with ASD have been reported to have NPHP1 duplications confirmed by a validation analysis $[7,13,14]$ (Table 1). The NPHP1 gene and its product are associated with the primary cilium and basal body $(\mathrm{PC} / \mathrm{BB})$ and subcellular organelles [15]. The $\mathrm{PC} / \mathrm{BB}$ control diverse cellular processes such as cell division, differentiation, migration, and planar cell polarity through signaling pathways $[11,15]$. These molecular findings and reports of the clinical phenotypes in patients with an altered NPHP1 gene support the hypothesis that the gene is associated with brain development and cognitive impairment. However, no functional study has reported a correlation between the NPHP1 gene and intelligence.

Of the six individuals who have been identified with ASD and NPHP1 duplications, one patient had a verbal intelligence quotient (VIQ) that was below average [7], one patient exhibited verbal dysfunction [13], and four other patients had intellectual disabilities [14]. We identified an NPHP1 duplication in two unrelated Japanese patients with ASD using a high-resolution single-nucleotide polymorphism array. One of these patients had a normal VIQ and performance IQ (PIQ). The other ASD patient had a normal VIQ, with a PIQ that was below average. As previously described, NPHP1 duplications have been observed in a number of ASD cohorts. No reports have delineated the clinical features of patients who harbor an NPHP1 duplication. Clinical data from patients with ASD will facilitate an understanding of the contribution of this

Table 1 Characteristics of individuals with a duplication of NPHP1 gene in our study and previous studies

\begin{tabular}{|c|c|c|c|c|c|c|c|}
\hline $\begin{array}{l}\text { Author, } \\
\text { year }\end{array}$ & $\begin{array}{l}\text { ID in the } \\
\text { study }\end{array}$ & Diagnosis & $\begin{array}{l}\text { Age } \\
\text { (years) }\end{array}$ & Gender & $\begin{array}{l}\text { Cognitive } \\
\text { profile }\end{array}$ & Dysmorphic features & Clinical profile \\
\hline \multirow{6}{*}{$\begin{array}{l}\text { Yasuda Y. } \\
\text { et al. } \\
2014\end{array}$} & \multirow[t]{3}{*}{ Patient 1} & \multirow[t]{3}{*}{ ASD } & \multirow[t]{3}{*}{24} & \multirow[t]{3}{*}{ Male } & FIQ 110 & \multirow{3}{*}{$\begin{array}{l}\text { No dysmorphic features were } \\
\text { observed }\end{array}$} & \multirow{3}{*}{$\begin{array}{l}\text { No evidence of epilepsy was } \\
\text { observed. The neurological } \\
\text { examination was normal. The } \\
\text { function of visceral organs, } \\
\text { including the kidneys, was normal }\end{array}$} \\
\hline & & & & & PIQ 98 & & \\
\hline & & & & & VIQ 117 & & \\
\hline & \multirow[t]{3}{*}{ Patient 2} & \multirow[t]{3}{*}{ ASD } & \multirow[t]{3}{*}{33} & \multirow[t]{3}{*}{ Male } & FIQ 80 & \multirow{3}{*}{$\begin{array}{l}\text { No dysmorphic features were } \\
\text { observed }\end{array}$} & \multirow{3}{*}{$\begin{array}{l}\text { No evidence of epilepsy was } \\
\text { observed. The neurological } \\
\text { examination was normal. The } \\
\text { function of visceral organs, } \\
\text { including the kidneys, was normal }\end{array}$} \\
\hline & & & & & VIQ 86 & & \\
\hline & & & & & PIQ 76 & & \\
\hline \multirow[t]{4}{*}{$\begin{array}{l}\text { Kaminsky } \\
\text { EB et al. } \\
2011[14]\end{array}$} & ISCA00000020 & ASD & NA & NA & $\begin{array}{l}\text { Intellectual } \\
\text { disability was } \\
\text { detected }\end{array}$ & NA & Developmental delay was observed \\
\hline & ISCA00000128 & ASD & NA & NA & $\begin{array}{l}\text { Intellectual } \\
\text { disability was } \\
\text { detected. }\end{array}$ & NA & Developmental delay was observed \\
\hline & ISCA00000949 & ASD & NA & NA & $\begin{array}{l}\text { Intellectual } \\
\text { disability was } \\
\text { detected }\end{array}$ & NA & Developmental delay was observed \\
\hline & ISCA00001175 & ASD & NA & NA & $\begin{array}{l}\text { Intellectual } \\
\text { disability was } \\
\text { detected }\end{array}$ & NA & Developmental delay was observed \\
\hline $\begin{array}{l}\text { Pinto D } \\
\text { et al. } \\
2010[7]\end{array}$ & \multirow[t]{2}{*}{$5036 \_4$} & Autism & NA & Male & $\begin{array}{l}\text { Below-average } \\
\text { VIQ and } \\
\text { average non- } \\
\text { verbal IQ were } \\
\text { detected }\end{array}$ & $\begin{array}{l}\text { No dysmorphic features were } \\
\text { observed }\end{array}$ & $\begin{array}{l}\text { No evidence of epilepsy was } \\
\text { observed }\end{array}$ \\
\hline $\begin{array}{l}\text { Baris H } \\
\text { et al. } \\
2006 \text { [13] }\end{array}$ & & $\begin{array}{l}\text { PDD/ } \\
\text { ADHD/ } \\
\text { Obsessive } \\
\text { compulsive } \\
\text { disorder }\end{array}$ & 12 & & $\begin{array}{l}\text { Language- } \\
\text { based learning } \\
\text { disability was } \\
\text { detected }\end{array}$ & $\begin{array}{l}\text { Mid-face hypoplasia, bilateral } \\
\text { epicanthal folds, long palpebral } \\
\text { fissures, synophrys, upturned nose } \\
\text { with a depressed nasal root and } \\
\text { retrognathia, and relative } \\
\text { macrocephaly were observed }\end{array}$ & $\begin{array}{l}\text { Speech delay and abnormal skin } \\
\text { lesions were observed. The } \\
\text { neurological examination was } \\
\text { normal. Brain MRI was normal. A } \\
\text { renal ultrasound scan was normal }\end{array}$ \\
\hline
\end{tabular}


CNV to the development of the disorder. To the best of our knowledge, this report is the first to describe ASD cases with NPHP1 duplications but without dysmorphic features or intellectual dysfunction.

\section{Case presentation}

Case 1

Patient 1 was a 24-year-old male with ASD. He was born vaginally at 37 weeks and had a birth weight of 2,190 g (-1.43 standard deviation, SD); his mother had pregnancy-induced hypertension. The family history was unremarkable. The patient began to walk independently at 15 months of age. During his childhood, he had difficulty with social communication and exhibited distress during the first grade from changes in the elementary school environment. He was first seen in the clinic when he was in the fifth grade because of the development of a tic, which improved without treatment. When the patient was a college senior, his symptoms worsened, and he was first diagnosed with ASD at 24 years of age by a child psychiatrist. At 26 years of age, his intellectual ability was within the normal range (a fullscale IQ (FIQ) of 110, a VIQ of 117, and a PIQ of 98). He was not dysmorphic. The neurological examination and the functioning of visceral organs, including the kidneys, were normal. Brain magnetic resonance imaging (MRI) at 24 years of age was reported as normal. His parents were phenotypically normal.

\section{Case 2}

Patient 2 was a 33-year-old male with ASD. He was delivered by Cesarean section, and neonatal asphyxia was caused by dystocia following an uneventful pregnancy. His birth weight was 4,070 g (+2.6 SD). The patient developed tics in elementary school and had difficulty with social communication. He was frequently a victim of bullying and exhibited distress over changes in his environment. At 17 years of age, he was diagnosed with schizophrenia, which resulted in repeated hospitalizations. When he was 33 years old, a new doctor noticed his communication impairments and stereotyped behaviors. The doctor initially referred him to a child psychiatrist, and his diagnosis was changed to ASD and schizophrenia.

At 36 years of age, his intellectual ability was within the normal range (FIQ, 80; VIQ, 86); his PIQ was below average (PIQ, 76). He had no dysmorphic features. The neurological examination and the functioning of visceral organs, including the kidneys, were normal. Brain MRI at 33 years of age was reported as normal. His father was phenotypically normal, whereas his mother was affected with schizotypal personality disorder.

\section{Assessment of ASD}

The patients were diagnosed by at least two trained child psychiatrists and/or child neurologists according to the criteria of the Diagnostic and Statistical Manual of Mental Disorders, 5th Edition (DSM-5). The assessments were performed using unstructured or semi-structured behavioral observation and interviews with the patients and their parents or caregivers [16]. Additionally, the participants met the ASD criteria of the Autism Diagnostic Interview-Revised (ADI-R) [17]. The Pervasive Developmental Disorders Autism Society Japan Rating Scale (PARS) [18] and the Japanese version of the Asperger's Questionnaire (AQ-J) [19] were used to evaluate ASD-specific behaviors and symptoms. The patients were recruited at Osaka University Hospital.

\section{Cognitive tests}

The Japanese version of the full-scale Wechsler Adult Intelligence Scale-III (WAIS-III) [20] was used to obtain the IQ data.

\section{Copy-number analysis}

Genomic DNA was extracted from whole blood using the QIAamp DNA Blood Maxi Kit (Qiagen, Hilden, Germany). The biological parentage was confirmed using nine polymorphic microsatellite markers (D1S450, D1S206, D5S630, D5S410, D9S285, D9S1776, D13S217, D14S276, and D14S985). The amplicons were separated on a Genetic Analyzer 3500 (Life Technologies, Inc., Carlsbad, CA, USA) and were analyzed using GeneMapper software, version 4.1 (Life Technologies, Inc.).

CNVs were analyzed using the CytoScan ${ }^{\text {Tm }} \mathrm{HD}$ array (Affymetrix, Santa Clara, CA, USA) and Chromosome Analysis Suite (ChAS) software, version 1.2 (Affymetrix) according to the manufacturer's instructions. The detection conditions in ChAS were set as follows: a confidence value of $90 \%, 20$ contiguous probes, and a size larger than $100 \mathrm{~kb}$ for duplications; and a confidence value of $89 \%, 20$ contiguous markers, and a size larger than $10 \mathrm{~kb}$ for deletions. The copy-number alterations detected by the microarray analysis were validated by quantitative real-time polymerase chain reaction (PCR) using Rotor-Gene Q (Qiagen). STXBP1 and FBN1 genes were used as reference genes. The PCR conditions and primer sequences are available upon request. Quantitative PCR was conducted in duplicate.

Using a high-resolution microarray analysis, we found a 110-862-kb duplication that involved the NPHP1 gene in these two patients (minimum, chr2 110, 873, 834-110, 983, 413 bp and maximum, chr2 110, 504, 317-111, 365, 995 bp based on the University of California Santa Cruz Genome Browser, build 37 [hg19]). The entire NPHP1 gene and the partial $M A L L$ gene are protein-coding genes that are located between two LCRs (see Additional 
file 1: Figure S1). We confirmed the presence of these de novo duplications in both patients using quantitative realtime PCR with DNA (see Additional file 2: Figure S2). Additionally, the biological parentage was confirmed.

\section{Conclusions}

We examined two Japanese ASD cases with NPHP1 duplications and delineated their clinical features. Previous studies have described ASD cases with NPHP1 duplications; however, these cases were associated with FIQ or VIQ impairment $[7,13,14]$. By contrast, we found that one patient with ASD in this study had an average intellectual ability. There is a possibility that the difference in cognitive ability could be caused by other genetic abnormalities and not by the NPHP1 gene. Details of microarray-based genomic profiling in the region of the duplication of the NPHP1 gene are shown in our two cases and six cases reported in previous studies (Additional file 3: Table S1). No specific gene, which is able to distinguish between our case with normal range of intellectual ability and cases in our study and previous studies with intellectual impairment, was found. We found a paternal CNV in our two cases in different region, where the genes did not exist, suggesting that no other gene might cause functional impact on this cognitive phenotype. On the other hand, the information of other CNVs present in six cases with intellectual impairment in previous studies was not available. It is possible that unknown CNVs other than duplication of the NPHP1 gene might be responsible for intellectual impairment in previous six cases.

One of the six previously described ASD cases had dysmorphic features [13]. An additional ASD case did not exhibit dysmorphic features [7], and data regarding dysmorphic features were not available for the other ASD cases [14] (Table 1). Our cases did not exhibit dysmorphic features. These findings suggest that patients with ASD and an NPHP1 duplication might not exhibit dysmorphic features. Previously described cases with NPHP1 duplications that were not associated with ASD demonstrated various phenotypes (Table 1) $[13,21]$. It is unclear whether an NPHP1 duplication is the causative factor of ASD.

The patients in this study had ASD features from early childhood; however, they were not diagnosed with ASD until adulthood. This delayed diagnosis might have resulted from the patients having an average FIQ. Individuals with ASD vary in intelligence, which ranges from having an intellectual disability to a high IQ [22]. Individuals with a normal or high IQ are frequently difficult to diagnose as having ASD. In addition, the diagnosis of ASD might not have been well understood during their childhood years, which could have resulted in a delayed diagnosis. Patient 2 suffered from schizophrenia and secondary ASD; a high rate of comorbidity with other psychiatric disorders has been observed in adults with ASD [23]. However, it is not possible to confirm whether this patient had two independent disorders. A duplication of the NPHP1 gene occurred in both cases in this study; however, this duplication has been observed in controls. To clarify whether the NPHP1 gene is a disease-causing gene or a disease-associated factor, further investigation of this locus in larger samples is warranted.

\section{Consent}

A description of the study was provided to each subject, and written informed consent was obtained from each subject regarding publication of this case report and any accompanying data. Peripheral blood samples from the patients and their families (when available) were collected after obtaining informed consent. This study was performed according to the Declaration of Helsinki of the World Medical Association; it was approved by the ethics committee at Osaka University and the institutional review board of Yokohama City University School of Medicine. Copies of the signed informed consent forms are available for review by the Editor-in-Chief of this journal.

\section{Additional files}

Additional file 1: Figure S1. De novo 2p13 duplication in two individuals with ASD. Single-nucleotide polymorphism array profiles in the 2 p13 region are shown for a control patient (top), patient 1 (second row), and patient 2 (third row). The location of NPHP1, other genes, and low-copy repeats (LCRs) (gray box) are depicted based on the University of California Santa Cruz Genome Browser, build 37 (hg19) (bottom).

Additional file 2: Figure S2. Confirmation of the de novo 2p13 duplication in two individuals with ASD. Gene expression was determined by quantitative real-time $P C R$, and the relative concentration of NPHP1 is shown on the Y-axis. Duplication was confirmed in the two patients (Pt 1 and Pt 2) with ASD.

Additional file 3: Table S1. Details of microarray-based genomic profiling in individuals with a duplication of the NPHP1 gene in this and previous studies.

\section{Abbreviations}

ADI-R: Autism Diagnostic Interview-Revised; AQ-J: Japanese version of the Asperger's Questionnaire; ASD: autism spectrum disorder; CNVs: copy-number variations; DSM-5: Diagnostic and Statistical Manual of Mental Disorders, 5th Edition; FIQ: full-scale intelligence quotient;

NPHP1: nephronophthisis 1; PARS: Pervasive Developmental Disorders Autism Society Japan Rating Scale; PIQ: performance intelligence quotient;

SD: standard deviation; VIQ: verbal intelligence quotient; WAIS-III: Wechsler Adult Intelligence Scale-III.

\section{Competing interests}

All authors declare that they have no competing interests.

\section{Authors' contributions}

$\mathrm{NM}, \mathrm{NM}$, and $\mathrm{RH}$ supervised the project and were critically involved in the design, analysis, interpretation, and coordination of the data. Additionally, they helped draft the manuscript. $\mathrm{RF}, \mathrm{RH}$, and $\mathrm{YY}$ wrote the draft of the manuscript. IM, MT, MT, NO, RH, YH, and $Y Y$ were critically involved in the 
data collection and interpretation. HS, MN, NM, NM, RF, and YT performed the molecular genetic analyses and interpreted the data. All of the authors read and approved the final manuscript.

\section{Acknowledgements}

We thank the patients and their families for participating in this study Additionally, we thank Ms. Y. Yamashita, Ms. E. Koike, Ms. S. Sugimoto, Ms. N. Watanabe, and Ms. K. Takabe for their technical assistance. This work was supported by research grants from the Japanese Ministry of Health, Labor, and Welfare (H22-seishin-ippan-001, H23-jitsuyouka (nanbyo)-ippan-005, H25shinkei kin-ippan-001), the Japan Society for the Promotion of Science (JSPS) through a Grant-in-Aid for Scientific Research [(A) (24249019), (B) (22390225, 25293250, 25293085, and 25293235), and (C) (24591680)] and a Challenging Exploratory Research grant (23659565), the Japanese Ministry of Education, Culture, Sports, Science, and Technology (MEXT) through a Grant-in-Aid for Scientific Research in Innovative Areas (Comprehensive Brain Science Network, 25129704) (Transcription Cycle, 12024421), Priority Areas-Research on the Pathomechanisms of Brain Disorders (18023045), the Strategic Research Program for Brain Sciences (11105137), the Fund for the Creation of Innovation Centers for Advanced Interdisciplinary Research Areas Program in the Project for Developing Innovation Systems, the Japan Foundation for Neuroscience and Mental Health, and the Takeda Science Foundation.

\section{Author details}

Department of Psychiatry, Osaka University Graduate School of Medicine, D3, 2-2, Yamadaoka, Suita, Osaka 565-0871, Japan. ${ }^{2}$ Molecular Research Center for Children's Mental Development, United Graduate School of Child Development, Osaka University, D3, 2-2,

Yamadaoka, Suita, Osaka 565-0871, Japan. ${ }^{3}$ Department of Human Genetics, Yokohama City University Graduate School of Medicine, 3-9 Fukuura, Kanazawa-ku, Yokohama 236-0004, Japan. ${ }^{4}$ Department of Neurology and Stroke Medicine, Yokohama City University Graduate School of Medicine, 3-9 Fukuura, Kanazawa-ku, Yokohama 236-0004, Japan. ${ }^{5}$ Division of Medical Genetics, Osaka Medical Center and Research Institute for Maternal and Child Health, Izumi 594-1101, Japan. ${ }^{6}$ Hiroshima Municipal Center for Child Health and Development, Hiroshima 732-0052, Japan. 'Department of Molecular Neuropsychiatry, Osaka University Graduate School of Medicine, D3, 2-2, Yamadaoka, Suita, Osaka 565-0871, Japan.

\section{Received: 3 May 2014 Accepted: 17 July 2014}

Published: 6 August 2014

\section{References}

1. Veenstra-Vanderweele J, Christian SL, Cook EH Jr: Autism as a paradigmatic complex genetic disorder. Annu Rev Genomics Hum Genet 2004, 5:379-405.

2. Baio J: Prevalence of autism spectrum disorders-Autism and Developmental Disabilities Monitoring Network, 14 sites, United States, 2008. MMWR Surveill Summ 2012, 61:1-19.

3. Elsabbagh M, Divan G, Koh YJ, Kim YS, Kauchali S, Marcin C, Montiel-Nava C, Patel V, Paula CS, Wang C, Yasamy MT, Fombonne E: Global prevalence of autism and other pervasive developmental disorders. Autism Res 2012, 5:160-179.

4. Xu LM, Li JR, Huang Y, Zhao M, Tang X, Wei L: AutismKB: an evidencebased knowledgebase of autism genetics. Nucleic Acids Res 2012, 40:D1016-D1022.

5. Levy D, Ronemus M, Yamrom B, Lee YH, Leotta A, Kendall J, Marks S, Lakshmi B, Pai D, Ye K, Buja A, Krieger A, Yoon S, Troge J, Rodgers L, lossifov I, Wigler M: Rare de novo and transmitted copy-number variation in autistic spectrum disorders. Neuron 2011, 70:886-897.

6. Sanders SJ, Ercan-Sencicek AG, Hus V, Luo R, Murtha MT, Moreno-De-Luca D, Chu SH, Moreau MP, Gupta AR, Thomson SA, Mason CE, Bilguvar K, Celestino-Soper PB, Choi M, Crawford EL, Davis L, Wright NR, Dhodapkar RM, DiCola M, DiLullo NM, Fernandez TV, Fielding-Singh V, Fishman DO, Frahm S, Garagaloyan R, Goh GS, Kammela S, Klei L, Lowe JK, Lund SC, et al: Multiple recurrent de novo CNVs, including duplications of the 7q1123 Williams syndrome region, are strongly associated with autism. Neuron 2011, 70:863-885.

7. Pinto D, Pagnamenta AT, Klei L, Anney R, Merico D, Regan R, Conroy J, Magalhaes TR, Correia C, Abrahams BS, Almeida J, Bacchelli E, Bader GD, Bailey AJ, Baird G, Battaglia A, Berney T, Bolshakova N, Bölte S, Bolton PF, Bourgeron T, Brennan S, Brian J, Bryson SE, Carson AR, Casallo G, Casey J,
Chung $\mathrm{BH}$, Cochrane L, Corsello C, et al: Functional impact of global rare copy number variation in autism spectrum disorders. Nature 2010, 466:368-372.

8. Girirajan S, Brkanac Z, Coe BP, Baker C, Vives L, Vu TH, Shafer N, Bernier R, Ferrero GB, Silengo M, Warren ST, Moreno CS, Fichera M, Romano C, Raskind WH, Eichler EE: Relative burden of large CNVs on a range of neurodevelopmental phenotypes. PLoS Genet 2011, 7:e1002334.

9. Basu SN, Kollu R, Banerjee-Basu S: AutDB: a gene reference resource for autism research. Nucleic Acids Res 2009, 37:D832-D836.

10. Saunier S, Calado J, Benessy F, Silbermann F, Heilig R, Weissenbach J, Antignac C: Characterization of the NPHP1 locus: mutational mechanism involved in deletions in familial juvenile nephronophthisis. Am J Hum Genet 2000, 66:778-789.

11. Sang L, Miller JJ, Corbit KC, Giles RH, Brauer MJ, Otto EA, Baye LM, Wen X, Scales SJ, Kwong M, Huntzicker EG, Sfakianos MK, Sandoval W, Bazan JF, Kulkarni P, Garcia-Gonzalo FR, Seol AD, O'Toole JF, Held S, Reutter HM, Lane WS, Rafiq MA, Noor A, Ansar M, Devi AR, Sheffield VC, Slusarski DC, Vincent $J B$, Doherty DA, Hildebrandt F, et al: Mapping the NPHP-JBTS-MKS protein network reveals ciliopathy disease genes and pathways. Cell 2011 145:513-528.

12. Tory $K$, Lacoste $T$, Burglen L, Morinière $V$, Boddaert N, Macher MA, Llanas B, Nivet $H$, Bensman A, Niaudet P, Antignac C, Salomon R, Saunier S: High NPHP1 and NPHP6 mutation rate in patients with Joubert syndrome and nephronophthisis: potential epistatic effect of NPHP6 and AHI1 mutations in patients with NPHP1 mutations. J Am Soc Nephrol 2007, 18:1566-1575

13. Baris H, Bejjani BA, Tan WH, Coulter DL, Martin JA, Storm AL, Burton BK, Saitta SC, Gajecka M, Ballif BC, Irons MB, Shaffer LG, Kimonis VE: Identification of a novel polymorphism-the duplication of the NPHP1 (nephronophthisis 1) gene. Am J Med Genet A 2006, 140A:1876-1879.

14. Kaminsky EB, Kaul V, Paschall J, Church DM, Bunke B, Kunig D, Moreno-DeLuca D, Moreno-De-Luca A, Mulle JG, Warren ST, Richard G, Compton JG, Fuller AE, Gliem TJ, Huang S, Collinson MN, Beal SJ, Ackley T, Pickering DL, Golden DM, Aston E, Whitby H, Shetty S, Rossi MR, Rudd MK, South ST, Brothman AR, Sanger WG, lyer RK, Crolla JA, et al: An evidence-based approach to establish the functional and clinical significance of copy number variants in intellectual and developmental disabilities. Genet Med 2011, 13:777-784.

15. Doherty D: Joubert syndrome: insights into brain development, cilium biology, and complex disease. Semin Pediatr Neurol 2009, 16:143-154.

16. Yasuda $Y$, Hashimoto $R$, Yamamori $H$, Ohi K, Fukumoto M, Umeda-Yano S, Mohri I, Ito A, Taniike M, Takeda M: Gene expression analysis in lymphoblasts derived from patients with autism spectrum disorder. Mol Autism 2011, 2:9.

17. Lord C, Rutter M, Le Couteur A: Autism Diagnostic Interview-Revised: a revised version of a diagnostic interview for caregivers of individuals with possible pervasive developmental disorders. J Autism Dev Disord 1994, 24:659-685.

18. Yamada A, Suzuki M, Kato M, Tanaka S, Shindo T, Taketani K, Akechi T, Furukawa TA: Emotional distress and its correlates among parents of children with pervasive developmental disorders. Psychiatry Clin Neurosci 2007, 61:651-657

19. Wakabayashi A, Tojo Y, Baron-Cohen S, Wheelwright S: [The Autism-Spectrum Quotient (AQ) Japanese version: evidence from high-functioning clinical group and normal adults]. Shinrigaku Kenkyu 2004, 75:78-84

20. Wechsler D: Wechsler Adult Intelligence Scale - Third Edition, Manual. San Antonio: The Psychological Corporation; 1997.

21. Roberts JL, Hovanes K, Dasouki M, Manzardo AM, Butler MG: Chromosomal microarray analysis of consecutive individuals with autism spectrum disorders or learning disability presenting for genetic services. Gene 2014, 535:70-78

22. Chakrabarti S, Fombonne E: Pervasive developmental disorders in preschool children: confirmation of high prevalence. Am J Psychiatry 2005, 162:1133-1141.

23. Lugnegard T, Hallerback MU, Gillberg C: Psychiatric comorbidity in young adults with a clinical diagnosis of Asperger syndrome. Res Dev Disabil 2011, 32:1910-1917.

doi:10.1186/s12991-014-0022-2

Cite this article as: Yasuda et al.: Duplication of the NPHP1 gene in patients with autism spectrum disorder and normal intellectual ability: a case series. Annals of General Psychiatry 2014 13:22. 